\title{
ANALYSIS OF THE EFFECT OF INCIDENCE ANGLE AND MOISTURE CONTENT ON THE PENETRATION DEPTH OF L- AND S-BAND SAR SIGNALS INTO THE GROUND SURFACE
}

\author{
Abhilash Singh ${ }^{1 *}$ Ganesh Kumar Meena ${ }^{1}$, Shashi Kumar ${ }^{2}$, Kumar Gaurav $^{1}$ \\ ${ }^{1}$ Indian Institute of Science Education and Research, Department of Earth and Environmental Sciences, Bhopal, India \\ - (sabhilash,gkmeena,kgaurav)@iiserb.ac.in \\ ${ }^{2}$ Indian Institute of Remote Sensing, ISRO, Dehradun 248001, India. - shashi@iirs.gov.in
}

Commission V, WG SS: Natural Resources Management

KEY WORDS: Soil moisture, Penetration depth, Volumetric moisture content, Soil texture, Incidence angle, SAR

\begin{abstract}
:
We study the functional relationship between the dielectric constant of soil-water mixture and penetration depth of microwave signals into the ground at different frequency (L\&S) band and incidence angles. Penetration depth of microwave signals into the ground depends on the incidence angle and wavelength of radar pulses and also on the soil properties such as moisture content and textural composition. It has been observed that the longer wavelengths have higher penetration in the soil but the penetration capability decreases with increasing dielectric behaviour of the soil. Moisture content in the soil can significantly increase its dielectric constant. Various empirical models have been proposed that evaluate the dielectric behaviour of soil-water mixture as a function of moisture content and texture of the soil. In this analysis we have used two such empirical models, the Dobson model and the Hallikainen model, to calculate the penetration depth at L- and C-band in soil and compared their results. We found that both of these models give different penetration depth and show different sensitivity towards the soil composition. Hallikainen model is more sensitive to soil composition as compared to Dobson model. Finally, we explore the penetration depth at different incidence angle for the proposed L- and S-band sensor of upcoming NASA-ISRO Synthetic Aperture Radar (NISAR) mission by using Hallikainen empirical model. We found that the soil penetration depth of SAR signals into the ground decreases with the increase in soil moisture content, incident angle and frequency.
\end{abstract}

\section{INTRODUCTION}

Penetration depth of microwave signals into the ground vary significantly with the moisture available in the soil. Soil moisture is a measure of temporary storage of water contained in the soil pores (Srivastava et al., 2006). It is a major component of soil that supports the growth of plants and helps to predict droughts. Each plant species requires a different range of soil-water for efficient absorption of water and nutrients. Some of them require dry roots with minimum soil moisture, whereas some require wet roots to stabilize the plant. On the basis of the soil moisture content, we can easily estimate the type of plant species that is expected to grow in a habitat. The first $200 \mathrm{~cm}$ of soil from the ground surface is classified as "root zone soil moisture" and serves as an important component of the Earth's critical zone. Moisture in this zone describes the water that is available for crops and plants. During drought, there is a deficit of moisture in the root zone which results in the depletion of crop production. Moisture in root zones also regulates the soil temperature that helps in the chemical and biological activities of the soil. Therefore a continuous monitoring of soil moisture in the root zone is required on regular basis to improve the crop yield forecasting and irrigation planning ( $\mathrm{SU}$ et al., 2014).

There are generally two approaches that are used to quantify soil moisture namely in-situ and remote sensing approach. In-situ measurement involves various point measurement methods to estimate the soil moisture. Gravimetric methods of soil moisture estimation is most widely used in-situ approach and considered

\footnotetext{
*Abhilash Singh
}

as the benchmark for calibration of all other soil moisture estimation techniques. In-situ techniques are useful for the estimation of soil moisture on a local scale, it is less accurate when applied to large spatial scale and it requires large number of samples to characterize an area. Recent advancement in the satellite and airborne remote sensing enable the mapping of soil moisture at regional as well as global scale with higher accuracy. Soil moisture estimation either by satellite or airborne remote sensing depends on the quantification of the electromagnetic (EM) energy that has been either emitted or reflected from the soil surface. One of such remote sensing techniques is microwave imaging that uses EM radiation of greater wavelength $(1 \mathrm{~mm}-1 \mathrm{~m})$ as compared to visible and infra-red radiation. SAR sensor is the most commonly used microwave imaging sensor. It transmits signals in the microwave band of EM spectrum and records the backscattered value. This backscattered value is related to the dielectric constant which can be used to estimate soil moisture.

Several models have been proposed to formulate the dielectric behaviour of soil-water mixtures in the microwave region of EM spectrum. For example, Dobson et al., (1984) examined the effect of soil texture on microwave emission and backscattering. They have established an empirical relation for the estimation of real and imaginary part of the dielectric constant at frequencies 1.4 and $5 \mathrm{GHz}$ (Dobson et al., 1984). Later, Hallikainen et al., (1985) expressed the dielectric behaviour of soil-water mixture as a function of moisture content and soil texture. They established an empirical relation for dielectric constant of soil samples measured at frequencies between 1.4 and $18 \mathrm{GHz}$ (Hallikainen et al., 1985). 
We recalculate the soil penetration depth at $\mathrm{L}$ - and C-band using both these empirical models (Dobson et al., 1984, Hallikainen et al., 1985) at different incident angles. We then compare the sensitivity of these two models in estimating the penetration depth into the ground in L-band and with varying soil textural composition. Finally, we have calculated the ground penetration depth for L- and S-band at different incidence angle using Hallikainen empirical model.

\section{THEORITICAL BACKGROUNG AND METHOD}

\subsection{Dobson empirical model}

Dobson et al., (1984) proposed an empirical model that relates soil dielectric constant and volumetric moisture content. The Dobson model reads;

$$
\begin{aligned}
\epsilon=a_{0} & +\left(a_{1}+b_{1} S+c_{1} C\right) w \\
& +\left(a_{2}+b_{2} S+c_{2} C\right) w^{2} \\
& +\left(a_{3}+b_{3} S+c_{3} C\right) w^{3}
\end{aligned}
$$

where $S$ and $C$ is the percentage of sand and clay respectively. $w$ is the volumetric water content (VWC) in $\left[\mathrm{m}^{3} / \mathrm{m}^{3}\right]$. Other terms $a_{0}, a_{1}, a_{2}, b_{1}, b_{2}, b_{3}, c_{1}, c_{2}$, and $c_{3}$ are constant factors and calibrated for real $\left(\epsilon^{\prime}\right)$ and imaginary part $\left(\epsilon^{\prime \prime}\right)$ of the dielectric constant at frequencies $1.4 \mathrm{GHz}$ (L-band) and $5 \mathrm{GHz}$ (C-band).

For frequency $1.4 \mathrm{GHz}$, the dielectric constant (real and imaginary part) reads:

$$
\begin{aligned}
\epsilon_{1.4 G H z}^{\prime}=2.37+ & (-5.24+0.55 S-0.15 C) w \\
+ & (146.04-0.74 S-0.85 C) w^{2} \\
\epsilon_{1.4 G H z}^{\prime \prime}=0.06+ & (6.69+0.0367 S-0.0620 C) w \\
+ & (16.17-0.30 S+0.27 C) w^{2}
\end{aligned}
$$

Similarly, for frequency $5 \mathrm{GHz}$, the dielectric constant (real and imaginary part) reads:

$$
\begin{gathered}
\epsilon_{5 G H z}^{\prime}=2.46+(13.07+0.14 S-0.44 C) w \\
+(132.11+0.38 S+C) w^{2} \\
+(-103.86-1.16 S-0.49 C) w^{3} \\
\epsilon_{5 G H z=0.12+}^{\prime \prime}(4.7+0.0646 S-0.2356 C) w \\
+(30.65-0.61 S+1.12 C) w^{2} \\
+(-34.29+1.36 S-1.16 C) w^{3}
\end{gathered}
$$

\subsection{Hallikainen empirical model}

Hallikainen et al., (1985) proposed a quadratic polynomial fitting model (7) based on different textural composition of the soil to compute the dielectric constant of soil-water mixture. The coefficients of the equation are calibrated for entire RADAR band but for a discrete set of frequencies bands such as, $(1.4 \mathrm{GHZ}, \mathrm{L}),(4$ $\mathrm{GHz}, \mathrm{S}),(6$ and $8 \mathrm{GHz}, \mathrm{C}),(10$ and $12 \mathrm{GHz}, \mathrm{X})$ and $(14,16$ and $18 \mathrm{GHz}, \mathrm{Ku}$ ). The Hallikainen model reads;

$$
\begin{array}{r}
\epsilon=\left(a_{0}+a_{1} S+a_{2} C\right) \\
+\left(b_{0}+b_{1} S+b_{2} C\right) w \\
+\left(c_{0}+c_{1} S+c_{2} C\right) w^{2}
\end{array}
$$

where $S$ and $C$ represents the percentage of sand and clay respectively. Other terms $a_{0}, a_{1}, a_{2}, b_{1}, b_{2}, b_{3}, c_{1}, c_{2}$, and $c_{3}$ are constant factors and calibrated for real and imaginary part of the dielectric constant for frequencies ranging from $1.4 \mathrm{GHz}$ to 18 $\mathrm{GHz}$.

For $1.4 \mathrm{GHz}$ (L-band), the Hallikainen equation to compute the dielectric constant (real and imaginary) reads;

$$
\begin{array}{r}
\epsilon_{1.4 G H z}^{\prime}=(2.862-0.012 S+0.001 C) \\
+(3.803+0.462 S-0.341 C) w \\
+(119.006-0.500 S+0.633 C) w^{2} \\
\epsilon_{1.4 G H z}^{\prime \prime}=(0.356-0.003 S-0.008 C) \\
+(5.507+0.044 S-0.002 C) w \\
+(17.753-0.313 S+0.206 C) w^{2}
\end{array}
$$

Similarly, for $6 \mathrm{GHz}$ (C-band), the Hallikainen equation to compute the dielectric constant (real and imaginary) reads;

$$
\begin{array}{r}
\epsilon_{6 G H z}^{\prime}=(1.993+0.002 S+0.015 C) \\
+(38.086-0.176 S-0.633 C) w \\
+(10.720+1.256 S+1.522 C) w^{2} \\
\epsilon_{6 G H z}^{\prime \prime}=(-0.123+0.002 S+0.003 C) \\
+(7.502-0.058 S-0.116 C) w \\
+(2.942-0.452 S+0.543 C) w^{2}
\end{array}
$$

Both these empirical models (Dobson et al., 1984, Hallikainen et al., 1985) are valid only up to a VWC of $50 \%$ (Nolan and Fatland, 2003).

\subsection{NISAR Mission: An Overview}

The NISAR mission is a joint collaboration between the National Aeronautics and Space Administration (NASA) and the Indian Space Research Organization (ISRO). It is a multi-disciplinary radar mission. The complete NISAR system consists of a dual frequency (L- and S-band), fully polarimetric radar, with an imaging swath greater than $240 \mathrm{~km}$. The combination of L- and Sband imagery will allow estimating depth dependent soil moisture variability and will help to isolate and remove soil moisture phase noise in targeted deformation interferograms. The presence of L-band SAR sensor will ensure sensing of soil moisture from deeper layers as compared to shorter wavelengths. According to the NISAR mission science user handbook, the frequency used for L- and S-band is $1.25 \mathrm{GHz}$ and $3.22 \mathrm{GHz}$ respectively with variation in the incident angle of $33^{0}$ to $47^{\circ}$ for both Land S-band (Falk, 2018). In this study, we have considered a frequency of $1.4 \mathrm{GHz}$ in L-band and $4 \mathrm{GHz}$ in S-band with variation in the incident angle of $33^{0}$ to $47^{0}$ for both L- and S-band. This consideration is because of the constraint on the empirical model. NISAR system will provide complete global coverage in a 12 day exact repeat period to generate interferometric timeseries and perform systematic global mapping of the changing 
surface of the Earth. It is the first NASA radar mission that studies systematically and globally about the solid Earth, ecosystems and ice masses. It will measure ice mass, the land surface motions and changes, ecosystem disturbances, and biomass explaining the underlying processes. These measurements will improve the forecast and assessment of changing ecosystems, the response of ice sheets, and natural hazards like floods, drought etc.

\subsection{Soil moisture and penetration depth of Microwave pulses}

The soil may be homogeneous or non-homogeneous. In homogeneous soil, we assume uniform properties with depth whereas non-homogeneous soil have layered structures having transmission losses. For simplicity, we will adhere to homogeneous soil. The power $\left(P_{p}\right)$ of an EM wave of a known polarization $(p)$, in homogeneous soil, transmitted at a depth $d$ is given by (Bruckler et al., 1988)

$$
P_{p}=P_{o p} * \gamma * e^{-2 j K_{z} d}
$$

where $\gamma$ represents the transmissivity at the air-soil interface, $j$ is the complex number, $P_{o p}$ is the power of the incident EM wave with known polarization $(p) . \quad K_{z}$ is the $z$ component of wave number in soil, given by (Ulaby et al., 1981)

$$
K_{z}=\sqrt{\omega^{2} \mu_{\epsilon_{0}} \epsilon_{1}-K_{0}^{2} \sin ^{2} \theta_{i}}
$$

where $\theta_{i}$ is the incident angle of the EM wave at the air-soil interface, $K_{0}$ is the wave number given by $2 \pi / \lambda, \omega$ is the angular frequency, $\epsilon_{0}$ is permittivity of the free air, $\epsilon_{1}$ is the relative dielectric constant, $\mu_{1}=\mu_{0}$ represent the magnetic permeability. Depth of penetration, $\delta_{p}$, of an EM wave is defined as the depth at which the power of the incident EM is reduced by $1 / e=(0.37)$ or to $37 \%$. This penetration depth is significantly different from skin depth, $\delta_{a}$. The skin depth is defined as the depth at which the amplitude of EM is reduced by $1 / e=(0.37)$ or to $37 \%$. $\delta_{p}$ is estimated by assuming a homogeneous soil profile at nadir incidence angle and it only considers the absorption by the soil. The absorption is because of the conductive properties of soil. The conductive properties of the soil reduces the intensity of the EM wave. This reduced energy is converted to another form, such as heat, and not backscattered. This loss depends on frequency, $\epsilon$, ratio of $\epsilon^{\prime \prime} / \epsilon^{\prime}$ (loss tangent:tan $\delta$ ) and incident angle $\theta_{i}$. Penetration depth is reached when

$$
\frac{P_{p}}{\left(P_{o p} * \gamma\right)}=e^{-1}
$$

Comparing Equation 13 with Equation 11 we get;

$$
2 j K_{z} d=1
$$

from Equation 14 and Equation 12 we get;

$$
\frac{2 \pi}{\lambda}|\operatorname{Im}[\sqrt{\epsilon}]| d=\frac{1}{2}
$$

The value of $d$ for which Equation 15 and Equation 14 hold is $\delta_{p}$. $\delta_{p}$ can be expressed as

$$
\delta_{p}=\frac{\lambda}{4 \pi} \sqrt{\left[\left(1+\left(\frac{\epsilon^{\prime \prime}}{\epsilon^{\prime}}\right)^{2}\right)^{1 / 2}-1\right] \frac{\epsilon^{\prime}}{2}}
$$

Assuming that $\tan \delta$ is less than $0.1\left(\mathrm{e} . \mathrm{g} \epsilon^{\prime \prime} / \epsilon^{\prime} \ll 0.1\right)$. $\delta_{p}$ can be expressed as

$$
\delta_{p}=\frac{\lambda * \sqrt{\epsilon^{\prime}}}{2 \pi * \epsilon^{\prime \prime}}
$$

where $\delta_{p}$ and $\lambda$ both are in millimetres. Due to the huge difference between the permittivity or dielectric constant of soil and water, and because the amount of water in soil is variable, soil moisture dominantly controls the permittivity of the soil and thus penetration depth as well.

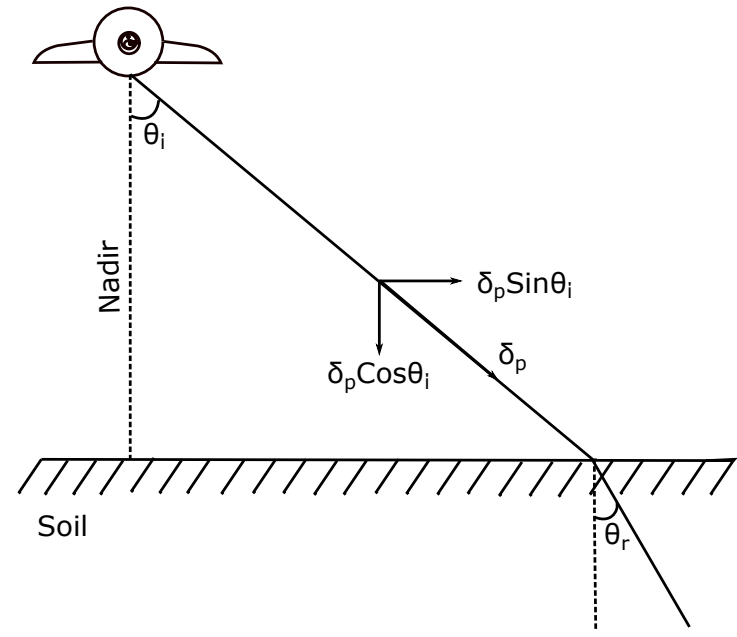

Figure 1. Relationship between incidence angle and penetration depth

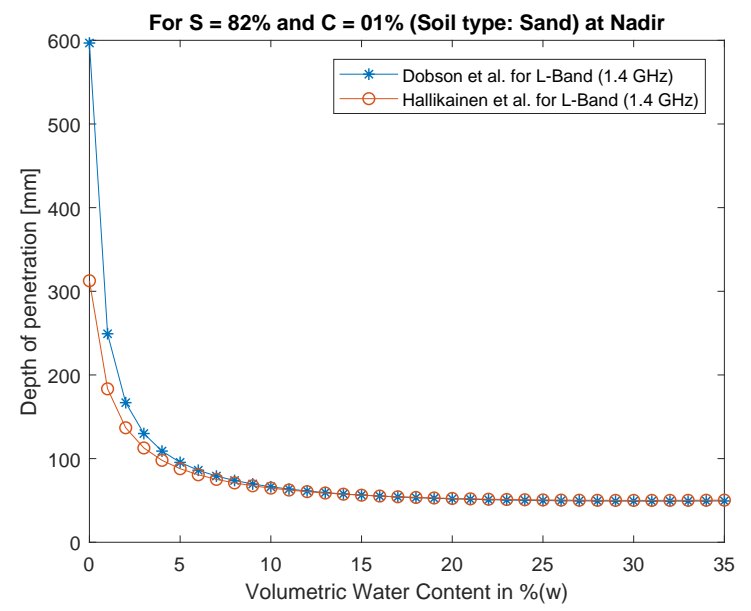

Figure 2. $\delta_{p}$ Vs VWC For $\mathrm{S}=82 \%$ and $\mathrm{C}=01 \%$ (Soil type: Sand) at Nadir

\subsection{Effect of incidence angle on penetration depth of Mi- crowave pulses}

Equation 17 represents the penetration depth at nadir incidence angle (e.g $\left.\theta_{i}=0\right)$. But the penetration depth changes with change in incidence angle. Using vector decomposition, we can extend the Equation 17 to estimate the penetration depth at different incidence angle.

From Figure 1, we have

$$
\delta_{p}^{\prime} \approx \delta_{p} * \cos \theta_{r}
$$




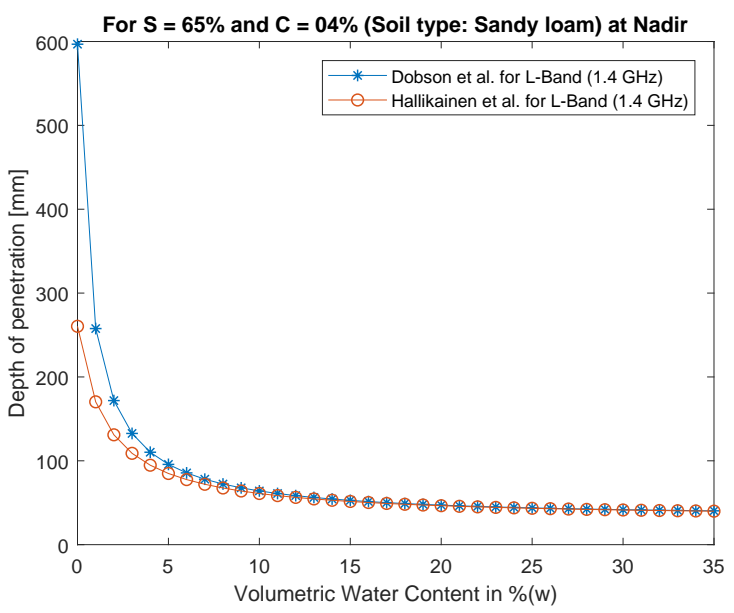

Figure 3. $\delta_{p}$ Vs VWC For $\mathrm{S}=65 \%$ and $\mathrm{C}=04 \%$ (Soil type: Sandy loam) at Nadir

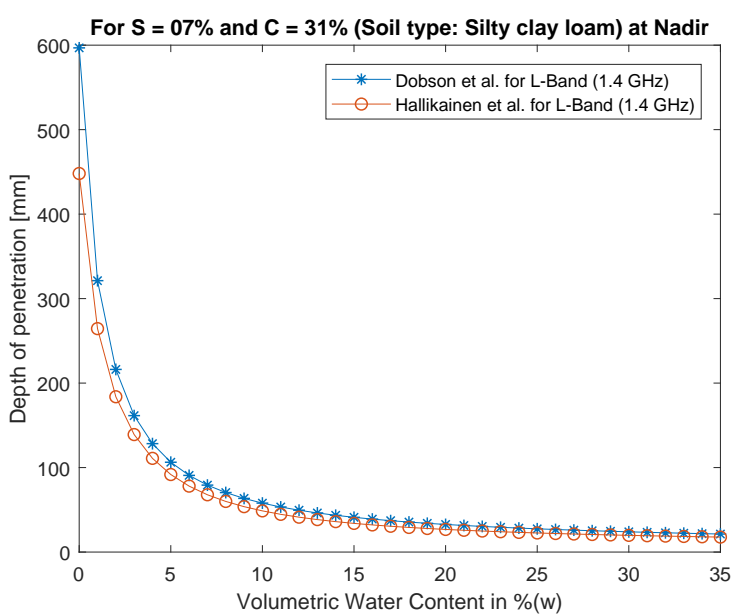

Figure 4. $\delta_{p}$ Vs VWC For $\mathrm{S}=07 \%$ and $\mathrm{C}=31 \%$ (Soil type: Silty clay loam) at Nadir

where $\delta_{p}$ represents the maximum depth within a medium at nadir incidence angle, $\delta_{p}^{\prime}$ represents the penetration depth at incidence angle, $\theta_{i}$ as from satellite, the incidence angle is different from Nadir and $\theta_{r}$ represents the angle of refraction.

Using Snell's law and $\epsilon^{\prime \prime} \ll \epsilon^{\prime}, \theta_{i} \approx \theta_{r}$. The Equation 18 can be written as

$$
\delta_{p}^{\prime} \approx \delta_{p} * \cos \theta_{i}
$$

Equation 19 allows to calculate the penetration depth for different incident angle.

\section{RESULTS AND CONCLUSION}

Using the equations (1-19), we can conclude that the relationship between penetration depth VWC is non-linear and varies considerably with the SAR wavelength.

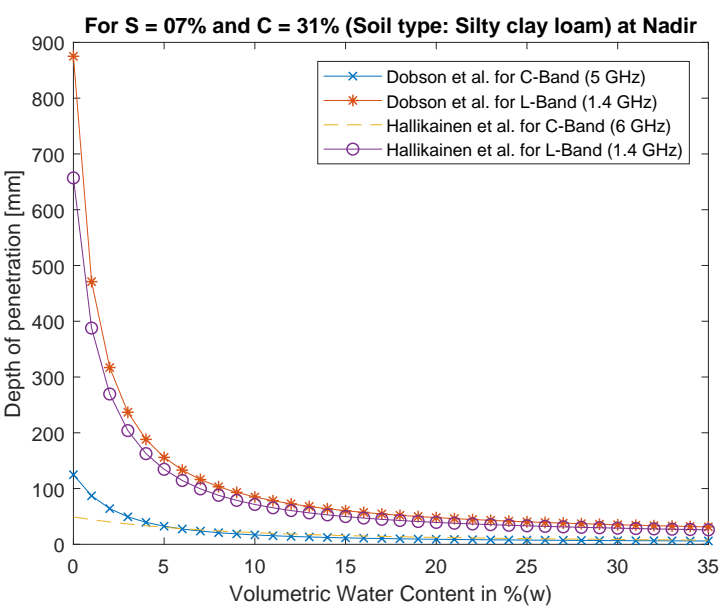

Figure 5. $\delta_{p}$ Vs VWC For $\mathrm{S}=07 \%$ and $\mathrm{C}=31 \%$ (Soil type: Silty clay loam) at Nadir

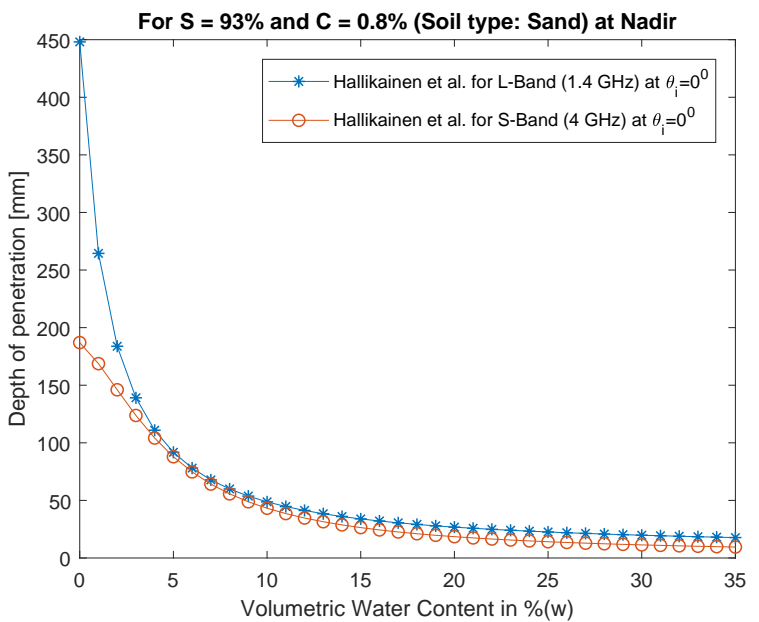

Figure 6. $\delta_{p}$ Vs VWC For $\mathrm{S}=93 \%$ and $\mathrm{C}=0.8 \%$ (Soil type: Sand) at Nadir

\subsection{Comparison of Dobson and Hallikainen models}

We have calculated the penetration depth of L-band $(1.4 \mathrm{GHz})$ SAR sensor into the ground by using the Dobson and Hallikainen empirical models. In doing so, we have considered three different types of soil samples, sandy (with sand $=82 \%$ and clay $=1 \%$ ), sandy loam ( sand $=65 \%$ and clay $=4 \%$ ) and silty clay loam ( sand $=7 \%$ and clay $=31 \%$ ). The VWC of the soil varies from 0 (completely dry) to $35 \%$. We have performed this analysis for the different incidence angles $\theta_{i}=0^{\circ}$ (nadir), $\theta_{i}=33^{0}$ and $\theta_{i}=47^{0}$ ). Fig. (2-4) show the penetration depth as a function of moisture content for three different types of soil at nadir point. The complete results are presented in Tables (1-3).

The simulation results depict that a non-linear relationship exists between VWC and soil penetration depth. The soil penetration depth decreases with increase in soil moisture content. The decrease in the soil penetration depth is significant for the first $10 \%$ increase in VWC, however, further increase has a reduced effect on soil penetration depth. This trend is supported by the fact that when moisture content in the soil increases, it leads to high backscatter value and results in less penetration. As the water 


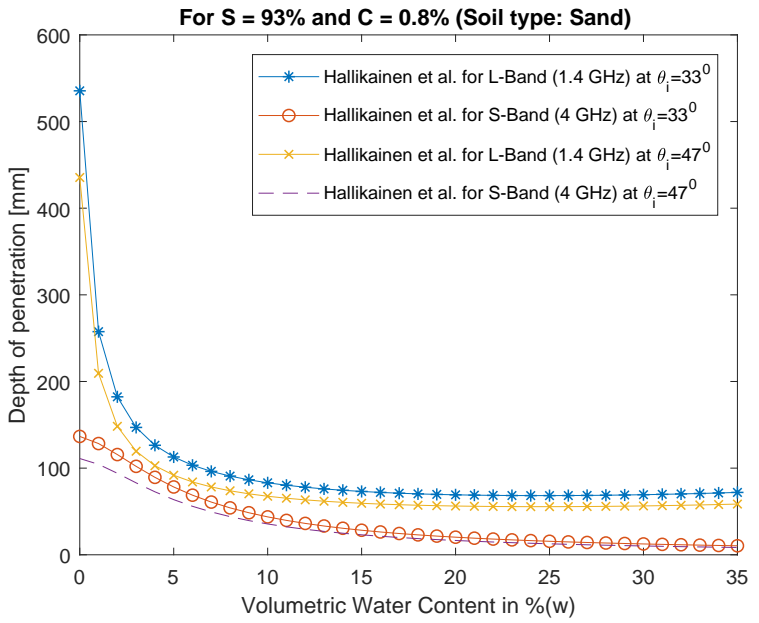

Figure 7. $\delta_{p}$ Vs VWC For $\mathrm{S}=93 \%$ and $\mathrm{C}=0.8 \%$ (Soil type: Sand)

Table 1. Observation Table for $\mathrm{S}=82 \%$ and $\mathrm{C}=01 \%$ (Soil type: Sand) (Simulation based)

\begin{tabular}{|c|c|c|c|}
\hline Band & $\begin{array}{c}\text { VWC } \\
(\%)\end{array}$ & $\begin{array}{c}\text { Incidence Angle } \\
\text { (in Degree) }\end{array}$ & $\begin{array}{c}\text { Penetration Depth } \\
(\mathrm{mm})\end{array}$ \\
\hline \multirow{4}{*}{$\begin{array}{c}\text { L[1.4 GHz] } \\
\text { in Dobson } \\
\text { empirical model }\end{array}$} & 0 & 0 & 875 \\
\cline { 2 - 4 } & 10 & 0 & 97 \\
\cline { 2 - 4 } & 15 & 33 & 734 \\
\cline { 2 - 4 } & 0 & 33 & 69 \\
\cline { 2 - 4 } & 15 & 47 & 597 \\
\hline \multirow{4}{*}{$\begin{array}{c}\text { L[1.4 GHz] } \\
\text { in Hallikainen }\end{array}$} & 0 & 0 & 458 \\
\cline { 2 - 4 } & 10 & 0 & 95 \\
\cline { 2 - 4 } & 15 & 33 & 694 \\
\cline { 2 - 4 } & 0 & 33 & 313 \\
\cline { 2 - 4 } & 15 & 47 & 56 \\
\hline
\end{tabular}

content in the soil changes from zero to non-zero, there is a significant increase in the imaginary part of the permittivity. This results in the decrease in soil penetration depth. The penetration depth also decreases with increase in the incidence angle.

Tables (1-3) show that for a same set of VWC and incident angle, the results for Dobson and Hallikainen models is not coherent in L-band $(1.4 \mathrm{GHz})$. Dobson empirical model gives a higher penetration depth in the ground as compared to the Hallikainen model. In Dobson model, for completely dry soil (e.g VWC $=0 \%$ ) the penetration depth is about 875,734 and 597 mm for incidence angles $\theta_{i}=0^{\circ}, \theta_{i}=33^{\circ}$ and $\theta_{i}=47^{\circ}$ receptively Table (1-3). This can also be observed from Equation (1), if $w=0$ (e.g VWC $=0 \%$ ) then it becomes $\epsilon=a_{0}$. This means when VWC $=0 \%$ then dielectric constant becomes constant and it will give same penetration depth irrespective of soil texture. We did not observe this trend in Hallikainen empirical model, because if $w=0$ (e.g VWC $=0 \%$ ) in Equation (6) then it becomes $\epsilon=\left(a_{0}+a_{1} S+a_{2} C\right)$ which is not constant and depends on soil texture.

With decrease in the percentage of sand $(S)$ in soil, the penetration depth also decreases for the same set of VWC and incident angle in both the models. However, the rate of change is higher in case of Hallikainen empirical model. From the above two arguments, we can conclude that the sensitivity of Hallikainen empirical model is more towards the soil texture as compared to Dobson model. Finally we conclude this subsection with an overview of Fig. (5). In this figure we have compared penetration depth at
Table 2. Observation Table For $\mathrm{S}=65 \%$ and $\mathrm{C}=04 \%$ (Soil type: Sandy loam) (Simulation based)

\begin{tabular}{|c|c|c|c|}
\hline Band & $\begin{array}{c}\text { VWC } \\
(\%)\end{array}$ & $\begin{array}{c}\text { Incidence Angle } \\
\text { (in Degree) }\end{array}$ & $\begin{array}{c}\text { Penetration Depth } \\
(\mathrm{mm})\end{array}$ \\
\hline \multirow{4}{*}{$\begin{array}{c}\text { L[1.4 GHz] } \\
\text { in Dobson } \\
\text { empirical model }\end{array}$} & 0 & 0 & 875 \\
\cline { 2 - 4 } & 10 & 0 & 94 \\
\cline { 2 - 4 } & 0 & 33 & 734 \\
\cline { 2 - 4 } & 15 & 33 & 65 \\
\cline { 2 - 4 } & 15 & 47 & 597 \\
\hline \multirow{4}{*}{$\begin{array}{c}\text { L[1.4 GHz] } \\
\text { in Hallikainen } \\
\text { empirical model }\end{array}$} & 0 & 47 & 53 \\
\cline { 2 - 4 } & 10 & 0 & 382 \\
\cline { 2 - 4 } & 15 & 33 & 320 \\
\cline { 2 - 4 } & 0 & 33 & 63 \\
\cline { 2 - 4 } & 15 & 47 & 52 \\
\hline
\end{tabular}

Table 3. Observation Table For $\mathrm{S}=07 \%$ and $\mathrm{C}=31 \%$ (Soil type: Silty clay loam) (Simulation based)

\begin{tabular}{|c|c|c|c|}
\hline Band & $\begin{array}{c}\text { VWC } \\
(\%)\end{array}$ & $\begin{array}{c}\text { Incidence Angle } \\
\text { (in Degree) }\end{array}$ & $\begin{array}{c}\text { Penetration Depth } \\
(\mathrm{mm})\end{array}$ \\
\hline \multirow{4}{*}{$\begin{array}{c}\text { L[1.4 GHz }] \\
\text { in Dobson } \\
\text { empirical model }\end{array}$} & 0 & 0 & 875 \\
\cline { 2 - 4 } & 10 & 0 & 85 \\
\cline { 2 - 4 } & 0 & 33 & 734 \\
\cline { 2 - 4 } & 15 & 33 & 51 \\
\cline { 2 - 4 } & 15 & 47 & 597 \\
\hline \multirow{4}{*}{$\begin{array}{c}\text { L }[1.4 \mathrm{GHz}] \\
\text { in Hallikainen }\end{array}$} & 0 & 47 & 41 \\
\cline { 2 - 4 } & 10 & 0 & 657 \\
\cline { 2 - 4 } & 0 & 33 & 551 \\
\cline { 2 - 4 } & 15 & 33 & 42 \\
\cline { 2 - 4 } & 0 & 47 & 34 \\
\hline
\end{tabular}

both L- and C-band for silty clay loam (with $\mathrm{S}=07 \%$ and $\mathrm{C}=$ $31 \%$ ) at nadir. It also follows the same general trend. The penetration depth for C-band is less as compared to L-band as higher wavelength penetrates more as compared to shorter wavelength.

\subsection{Comparison of $\mathrm{L}$ - and S-band penetration depth using Hallikainen model}

Since Hallikainen empirical model is more sensitive towards the soil texture, we used this model to explore the penetration depth of L- and S-band. Penetration depth at L- and S-band for sandy soil type (with $\mathrm{S}=93 \%$ and $\mathrm{C}=0.8 \%$ ) at nadir is shown in Fig. (6) and at different incident angle $\left(33^{\circ}\right.$ and $\left.47^{\circ}\right)$ is shown in Fig. (7). From Table (4) we can observe that for dry soil or field, as the incident angle changes from $33^{0}$ to $47^{0}$ the soil penetration depth changes from $535 \mathrm{~mm}$ to $435 \mathrm{~mm}$ in L-band and from $137 \mathrm{~mm}$ to $111 \mathrm{~mm}$ in S-band. For $15 \%$ VWC as the incident angle changes from $33^{0}$ to $47^{0}$ the soil penetration depth changes from $73 \mathrm{~mm}$ to $59 \mathrm{~mm}$ in L-band and from $28 \mathrm{~mm}$ to $23 \mathrm{~mm}$ in S-band. At

Table 4. Observation Table For $\mathrm{S}=93 \%$ and $\mathrm{C}=0.8 \%$ (Soil type: Sand) (Simulation based)

\begin{tabular}{|c|c|c|c|}
\hline $\begin{array}{c}\text { Hallikainen } \\
\text { empirical model }\end{array}$ & $\begin{array}{c}\text { VWC } \\
(\%)\end{array}$ & $\begin{array}{c}\text { Incidence Angle } \\
\text { (in Degree) }\end{array}$ & $\begin{array}{c}\text { Penetration Depth } \\
(\mathrm{mm})\end{array}$ \\
\hline \multirow{4}{*}{$\begin{array}{c}\text { L-Band } \\
\text { at }[1.4 \mathrm{GHz}]\end{array}$} & 0 & 0 & 638 \\
\cline { 2 - 4 } & 10 & 0 & 99 \\
\cline { 2 - 4 } & 0 & 33 & 535 \\
\cline { 2 - 4 } & 15 & 33 & 73 \\
\cline { 2 - 4 } & 0 & 47 & 435 \\
\hline \multirow{4}{*}{$\begin{array}{c}\text { S-Band } \\
\text { at }[4 \mathrm{GHz}]\end{array}$} & 15 & 47 & 59 \\
\cline { 2 - 4 } & 10 & 0 & 163 \\
\cline { 2 - 4 } & 0 & 0 & 52 \\
\cline { 2 - 4 } & 15 & 33 & 28 \\
\cline { 2 - 4 } & 0 & 33 & 111 \\
\cline { 2 - 4 } & 15 & 47 & 23 \\
\hline
\end{tabular}


nadir incidence angle for a dry field, the soil penetration depth is $638 \mathrm{~mm}$ for L-band and $163 \mathrm{~mm}$ for S-band. We found that penetration depth varies considerably with SAR wavelength. Penetration depth is more in L-band SAR signal as compared with the S-band SAR signal. In general, the penetration depth decreases with increasing frequency. When the incidence angle is fixed at $33^{0}$, then for first $15 \%$ increase in the VWC there is $86.35 \%$ and $79.56 \%$ decrease in soil penetration depth in L- and S-band respectively whereas when the incidence angle is fixed at $47^{\circ}$, then for first $15 \%$ increase in the VWC there is $86.43 \%$ and $79.27 \%$ decrease in soil penetration depth in L- and S-band respectively. Usually, soil moisture is not constant with depth, it typically varies with depth, and this variation results in a noticeable effect on penetration depth. Although soil dielectric constant is calculated as a function of VWC and soil texture but much remains to be done in this regards especially if we can a incorporate soil roughness, and the presence of organic matter in estimation of soil dielectric constant.

\section{ACKNOWLEDGEMENTS}

This work was funded by the NASA-ISRO synthetic Aperture Radar (NISAR) mission through grant Hyd-01. We would like to acknowledge IISER Bhopal and IIRS Dehradun for all the necessary institutional support. AS would like to thank to Department of Science and Technology, Govt. of India for providing research fellowship as DST-INSPIRE fellow.

\section{REFERENCES}

Bruckler, L., Witono, H. and Stengel, P., 1988. Near surface soil moisture estimation from microwave measurements. Remote Sensing of Environment 26(2), pp. 101-121.

Dobson, M. C., Kouyate, F. and Ulaby, F. T., 1984. A reexamination of soil textural effects on microwave emission and backscattering. IEEE Transactions on Geoscience and Remote Sensing (6), pp. 530-536.

Falk, A., G. B. A. B. S. B. S. C. M. C. . H. Z., 2018. Nasa-isro sar ( nisar ) mission science users handbook. 22(2), pp. 1-350.

Hallikainen, M. T., Ulaby, F. T., Dobson, M. C., El-Rayes, M. A. and Wu, L.-K., 1985. Microwave dielectric behavior of wet soilpart 1: Empirical models and experimental observations. IEEE Transactions on Geoscience and Remote Sensing (1), pp. 25-34.

Nolan, M. and Fatland, D. R., 2003. Penetration depth as a dinsar observable and proxy for soil moisture. IEEE Transactions on Geoscience and Remote Sensing 41(3), pp. 532-537.

Srivastava, H. S., Patel, P. and Navalgund, R. R., 2006. How far sar has fulfilled its expectation for soil moisture retrieval. In: Microwave Remote Sensing of the Atmosphere and Environment $V$, Vol. 6410, International Society for Optics and Photonics, p. 641001.

SU, S. L., Singh, D. and Baghini, M. S., 2014. A critical review of soil moisture measurement. Measurement 54, pp. 92-105.

Ulaby, F. T., Moore, R. K. and Fung, A. K., 1981. Microwave remote sensing-active and passive-volume i-microwave remote sensing fundamentals and radiometry (v. 1).

\section{APPENDIX}

The complete MATLAB code is made available for all.(Download)

Revised September 2018 